\title{
PENGARUH DISIPLIN KERJA TERHADAP KINERJA KARYAWAN PADA PT. SENTRA PONSELINDO
}

\author{
1Yulia Aniasari, ${ }^{2 *}$ Retno Wulansari \\ Universitas Pamulang, Tangerang Selatan, Banten, Indonesia \\ *dosen00568@unpam.ac.id
}

\begin{abstract}
Abstrak
Tujuan penelitian ini untuk menganalisa pengaruh disiplin kerja terhadap kinerja karyawan pada PT. Sentra Ponselindo. Metode penelitian adalah metode asosiatif. Populasi dan sampel sebanyak 45 responden dan menggunakan teknik sampling jenuh. Hasil penelitian menunjukkan bahwa terdapat pengaruh positif dan signifikan antara disiplin kerja $(\mathrm{X})$ terhadap kinerja karyawan $(\mathrm{Y})$ pada PT Sentra Ponselindo, dengan persamaan regresi sederhana $Y=32,207+0,496 X$. Hasil uji hipotesis parsial menunjukkan nilai thitung 4,084 > t tabel 2,017 dengan taraf 5\% maka Ha diterima dan H0 ditolak, maka dalam penelitian ini menetapkan bahwa terdapat pengaruh positif dan signifikan antara disiplin kerja $(\mathrm{X})$ terhadap kinerja karyawan $(\mathrm{Y})$ pada PT Sentra Ponselindo.
\end{abstract}

Kata Kunci : Disiplin Kerja dan Kinerja

\section{Abstract}

The purpose of this study is to analyze the influence of work discipline on employee performance at PT. Mobile Center. The research method is an associative method. Population and sample as many as 45 respondents and using saturated sampling techniques. The results showed that there is a positive and significant influence between work discipline $(X)$ on employee performance $(Y)$ at PT Sentra Ponselindo, with a simple regression equation of $Y=32,207+0.496 X$. The partial hypothesis test result showed a value of thitung 4,084 $>t$ table 2,017 with a level of 5\% then $\mathrm{Ha}$ received and $\mathrm{HO}$ rejected, so in this study determined that there is a positive and significant influence between work discipline (X) on employee performance $(Y)$ at PT Sentra Ponselindo.

Keywords : Dicipline and Employee Performance

\section{PENDAHULUAN}

Transformasi Perusahaan-perusahaan saat ini, menghadapi persaingan usaha yang sangat ketat, dengan adanya perkembangan tekhnologi yang sangat pesat, serta era digitalilsasi. Agar tetap bertahan dan mencapai tujuan perusahaan, diperlukan dukungan dari tenaga kerja yang memiliki kemampuan dan keahlian yang mumpuni untuk dapat bersaing dan memberikan konsitribusi terhadap tujuan perusahaan. Bukan hal yang mudah bagi setiap perusahaan dalam memiliki tenaga kerja yang terampil sesuai dengan bidang kerja yang diperlukan perusahaan. Kinerja karyawan adalah kunci sukses perusahaan, dan disiplin kerja adalah faktor penting yang mempengaruhi kinerja karyawan.

Pentingnya disiplin kerja, bertujuan untuk meningkatkan efisiensi semaksimal mungkin dengan cara mencegah pemborosan waktu dan energi. Disiplin yang baik mencerminkan besarnya rasa tanggung jawab seseorang terhadap tugas tugas yang diberikan kepadanya. Menurut Hasibuan (2016 : 23), Kedisiplinan merupakan fungsi manejemen sumber daya manusia yang terpenting dan kunci terwujudnya tujuan karena tanpa disiplin yang baik sulit terwujud tujuan yang maksimal. Sutrisno (2017:89) mengatakan bahwa disiplin karyawan adalah perilaku seorang dengan peraturan, prosedur kerja yang ada atau disiplin adalah sikap, tingkah laku, dan perbuatan yang sesuai dengan peraturan dari organisasi baik tertulis maupun yang tidak tertulis.

Menurut Moekijat (2014:195), Disiplin berasal dari bahasa latin yaitu disciplina yang berarti latihan atau pendidikan 
kesopanan dan kerohanian serta pengembangan tabiat. Lazimnya kata discipline menunjukkan suatu ide hukuman, akan tetapi itu bukan arti disiplin sebenarnya. Menurut Wilson Bangun (2016:4), salah satu sumber daya organisasi yang memiliki peran penting dalam mencapai tujuannya adalah sumber daya manusia. Suatu cara yang berkaitan dengan sumber daya manusia agar dapat menjadi sumber keunggulan bersaing adalah melalui peningkatan modal manusia untuk dapat mengenal dan beradaptasi dengan lingkungan yang selalu berubah.

Menurut Sutrisno (2017:151), Kinerja adalah sebagai hasil yang telah dicapai seseorang dari tingkah laku kerjanya dalam melaksanakan aktivitas kerjanya. Sedangkan menurut Mangkunegara (2016:9), Kinerja adalah hasil kerja secara kualitas dan kuantitas yang dicapai oleh seorang pegawai dalam melaksanakan tugasnya sesuai dengan tanggung jawab yang diberikan kepadanya. Kinerja sebagai perwujudan perilaku kerja seorang karyawan yang ditampilkan sebagai prestasi kerja sesuai dengan peranannya dalam sebuah perusahaan dalam jangka waktu tertentu. Hal ini dikarenakan kinerja karyawan sebagai penentu keberhasilan serta kelangsungan hidup perusahaan.

PT Sentra Ponselindo, merupakan perusahaan yang bergerak dibidang jasa, pemasaran handphone dan asessoris handphone yang berlokasi di Tangerang. Selain mempunyai kompetensi pada jasa dan pemasaran, perusahaan memberikan perhatian khusus kepada pembinaan sumber daya manusia dalam proses untuk dapat memberikan pelayanan kepada pelanggan.

Dari pengamatan yang peneliti lakukan, saat ini terdapat ketidakpuasan dan kekecewaan karyawan. Hal tersebut tersebut ditunjukkan dengan tingkat ketidakhadiran karyawan selama ini yang relatif tinggi, penyelesaian pekerjaan yang tidak tepat waktu sehingga membutuhkan tambahan jam atau waktu kerja untuk menyelesaikan pekerjaan.
Berikut ini adalah data absensi karyawan PT Sentra Ponselindo. Terdapat jumlah ketidakhadiran karyawan yang tidak sesuai harapan perusahaan.

Tabel 1 Data Kehadiran karyawan

\begin{tabular}{|c|c|c|c|c|c|}
\hline Bulan & $\begin{array}{c}\text { Jml } \\
\text { karyawan }\end{array}$ & $\begin{array}{l}\text { Kehadiran } \\
\text { Karyawan }\end{array}$ & $\%$ & $\begin{array}{c}\text { Ketidak } \\
\text { hadiran } \\
\text { Karyawan }\end{array}$ & $\%$ \\
\hline May-17 & 52 & 41 & $79 \%$ & 11 & $21 \%$ \\
\hline Jun-17 & 52 & 45 & $87 \%$ & 7 & $13 \%$ \\
\hline Jul-17 & 53 & 48 & $91 \%$ & 5 & $9 \%$ \\
\hline Aug-17 & 53 & 47 & $89 \%$ & 6 & $11 \%$ \\
\hline Sep-17 & 53 & 47 & $89 \%$ & 6 & $11 \%$ \\
\hline Oct-17 & 53 & 45 & $85 \%$ & 8 & $15 \%$ \\
\hline Nov-17 & 53 & 53 & $100 \%$ & 0 & $0 \%$ \\
\hline Dec-17 & 53 & 53 & $100 \%$ & 0 & $0 \%$ \\
\hline Jan-18 & 52 & 50 & $96 \%$ & 2 & $4 \%$ \\
\hline Feb-18 & 52 & 50 & $96 \%$ & 2 & $4 \%$ \\
\hline Mar-18 & 51 & 48 & $94 \%$ & 3 & $6 \%$ \\
\hline Apr-18 & 51 & 46 & $90 \%$ & 5 & $10 \%$ \\
\hline May-18 & 51 & 47 & $92 \%$ & 4 & $8 \%$ \\
\hline Jun-18 & 50 & 45 & $90 \%$ & 5 & $10 \%$ \\
\hline Jul-18 & 50 & 43 & $86 \%$ & 7 & $14 \%$ \\
\hline Aug-18 & 49 & 45 & $92 \%$ & 4 & $8 \%$ \\
\hline Sep-18 & 49 & 45 & $92 \%$ & 4 & $8 \%$ \\
\hline Oct-18 & 49 & 43 & $88 \%$ & 6 & $12 \%$ \\
\hline Nov-18 & 47 & 41 & $87 \%$ & 6 & $13 \%$ \\
\hline Dec-18 & 47 & 46 & $98 \%$ & 1 & $2 \%$ \\
\hline Jan-19 & 46 & 46 & $100 \%$ & 0 & $0 \%$ \\
\hline Feb-19 & 46 & 40 & $87 \%$ & 6 & $13 \%$ \\
\hline Mar-19 & 46 & 42 & $91 \%$ & 4 & $9 \%$ \\
\hline Apr-19 & 45 & 44 & $98 \%$ & 1 & $2 \%$ \\
\hline
\end{tabular}

Sumber: PT Sentra Ponselindo, 2019

Berdasarkan tabel tersebut, di ketahui pada selama kurun waktu 2 (dua) tahun terakhir yaitu bulai Mei 2017 s/d April 2019 menunjukkan fluktuatif kehadiran kerja, dimana ketidakhadiran tertinggi pada bulan Mei 2017 sebesar 21\% dari jumlah karyawan. Masih kurangnya kehadiran kerja karyawan ini akan mengganggu proses kegiatan kerja dan kinerja karyawan dan pada akhirnya akan berdampak pada pencapaian target penjualan perusahaan.

Dari tabel tersebut menunjukkan bahwa kurang disiplinnya karyawan dalam kehadiran kerja ini sangat mengakibatkan kerugian bagi karyawan yang hadir lainnya, dimana perusahaan akan melimpahkan pekerjaan kepada karyawan yang hadir, sehingga volume pekerjaan dan waktu penyelesaian pekerjaan menjadi bertambah. Hal ini mengakibatkan biaya lembur akan bertambah.

Kinerja mencerminkan besarnya rasa tanggung jawab seseorang atau sekelompok orang dalam melaksanakan pekerjaan. 
Kinerja yang baik dan sesuai dengan standar pekerjaan memungkinkan karyawan akan mencapai hasil kerja yang sesuai dengan target yang telah ditetapkan.

Fenomena yang terjadi di tempat penelitian ini menujukkan masih naik turunnya hasil penjualan ponsel seluler dalam beberapa tahun ini. Berikut data penjualan hasil ponsel selular, data dirangkum seperti pada tabel dan gambar di bawah ini :

Tabel 2. Target dan Realisasi Penjualan

\begin{tabular}{|c|c|c|c|c|}
\hline Bulan & Target & $\begin{array}{c}\text { Pencapain Per } \\
\text { Bulan }\end{array}$ & Hasil & Sisa \\
\hline $\begin{array}{c}\text { May- } \\
17\end{array}$ & Rp 200,000,000 & Rp 170,000,000 & $85 \%$ & $-15 \%$ \\
\hline Jun-17 & Rp 200,000,000 & Rp $174,000,000$ & $87 \%$ & $-13 \%$ \\
\hline Jul-17 & Rp 200,000,000 & Rp 180,000,000 & $90 \%$ & $-10 \%$ \\
\hline Aug-17 & Rp 250,000,000 & $\mathrm{Rp} 217,500,000$ & $87 \%$ & $-13 \%$ \\
\hline Sep-17 & Rp 250,000,000 & $\operatorname{Rp} 215,000,000$ & $86 \%$ & $-14 \%$ \\
\hline Oct-17 & Rp 250,000,000 & Rp 212,500,000 & $85 \%$ & $-15 \%$ \\
\hline Nov-17 & Rp 300,000,000 & $\operatorname{Rp} 243,000,000$ & $81 \%$ & $-19 \%$ \\
\hline Dec-17 & $\operatorname{Rp} 300,000,000$ & Rp $240,000,000$ & $80 \%$ & $-20 \%$ \\
\hline Jan-18 & Rp $300,000,000$ & $\operatorname{Rp} 255,000,000$ & $85 \%$ & $-15 \%$ \\
\hline Feb-18 & $\operatorname{Rp} 300,000,000$ & Rp 240,000,000 & $80 \%$ & $-20 \%$ \\
\hline $\begin{array}{c}\text { Mar- } \\
18 \\
\end{array}$ & Rp $300,000,000$ & Rp 246,000,000 & $82 \%$ & $-18 \%$ \\
\hline Apr-18 & Rp $300,000,000$ & $\operatorname{Rp} 243,000,000$ & $81 \%$ & $-19 \%$ \\
\hline $\begin{array}{c}\text { May- } \\
18 \\
\end{array}$ & Rp $300,000,000$ & Rp 270,000,000 & $90 \%$ & $-10 \%$ \\
\hline Jun-18 & $\operatorname{Rp} 300,000,000$ & $\operatorname{Rp} 285,000,000$ & $95 \%$ & $-5 \%$ \\
\hline Jul-18 & Rp 300,000,000 & Rp 264,000,000 & $88 \%$ & $-12 \%$ \\
\hline Aug-18 & Rp 300,000,000 & Rp 261,000,000 & $87 \%$ & $-13 \%$ \\
\hline Sep-18 & Rp $300,000,000$ & $\operatorname{Rp} 270,000,000$ & $90 \%$ & $-10 \%$ \\
\hline Oct-18 & Rp 300,000,000 & Rp $261,000,000$ & $87 \%$ & $-13 \%$ \\
\hline Nov-18 & Rp $300,000,000$ & Rp $267,000,000$ & $89 \%$ & $-11 \%$ \\
\hline Dec-18 & p 300,000,000 & $\operatorname{Rp} 267,000,000$ & $89 \%$ & $-11 \%$ \\
\hline Jan-19 & Rp $300,000,000$ & Rp $270,000,000$ & $90 \%$ & $-10 \%$ \\
\hline Feb-19 & $\operatorname{Rp} 300,000,000$ & Rp 276,000,000 & $92 \%$ & $-8 \%$ \\
\hline $\begin{array}{c}\text { Mar- } \\
19 \\
\end{array}$ & Rp $300,000,000$ & $\operatorname{Rp} 261,000,000$ & $87 \%$ & $-13 \%$ \\
\hline Apr-19 & Rp $300,000,000$ & $\operatorname{Rp} 255,000,000$ & $85 \%$ & $-15 \%$ \\
\hline
\end{tabular}

Melihat tabel di atas menunjukkan dalam kurun waktu tahun 2017 s/d 2019, penjualan ponsel menunjukkan fluktuatif atau naik turun. Penjulan tertinggi pada tahun 2017 terjadi pada bulan Juli 2017 sebesar $90 \%$ dari taget dan terendah pada bulan November 2017 sebesar 81\% dari taget $100 \%$. Penjulan tertinggi pada tahun 2018 terjadi pada bulan Juni 2018 sebesar 95\% dari taget dan terendah pada bulan Februari 2018 sebesar $81 \%$ dari taget $100 \%$. Penjulan tertinggi pada tahun 2019 terjadi pada bulan Februari 2019 sebesar 92\% dari taget dan terendah pada bulan April 2019 sebesar $85 \%$ dari taget $100 \%$. Tidak tercapainya target yang ditetapkan, menujukkan masih kurang baiknya kinerja karyawan departemen sales penjulan dalam memasarkan produk ponsel seluler dan sejenisnya. Selain itu kurangnya pengetahuan dan keterampilan karyawan diduga menjadi penyebab naik turunnya penjualan ini. Hal ini disebabkan kurangnya ketelitian karyawan dalam mencari informasi mengenai spesifikasi produk yang dipasarkan kepada konsumen.

Berdasarkan permasalahan tersebut, maka peneliti tertarik untuk melakukan penelitian yang berjudul "Pengaruh Disiplin Kerja Terhadap Kinerja Karyawan Departemen Sales Pada PT. Sentra Ponselindo".

\section{TINJAUAN PUSTAKA}

1. Disiplin

Disiplin muncul sebagai usaha untuk memperbaiki perilaku individu sehingga taat azas dan selalu patuh pada aturan atau norma yang berlaku. Setiap perusahaan, selain harus memiliki modal yang kuat, perusahaan juga harus memiliki tenaga kerja yang terampil. Namun demikian, tenaga kerja yang terampil tidak cukup untuk membangun perusahaan, namun juga perusahaan harus memiliki tenaga kerja yang berdedikasi dan mempunyai kedisiplinan yang tinggi dalam melaksanakan pekerjaannya.

Disiplin menurut pendapat ahli, diantaranya: Menurut Hasibuan (2016:23), “Kedisiplinan merupakan fungsi manejemen sumber daya manusia yang terpenting dan kunci terwujudnya tujuan karena tanpa disiplin yang baik sulit terwujud tujuan yang maksimal". Indikator disiplin kerja menurut Hasibuan (2016:195), adalah a. Tujuan dan Kemampuan, b. Teladan Pimpinan, c. Balas Jasa, d. Keadilan, e. Waskat, f. Sanksi Hukuman, g. Ketegasan, h. Hubungan Kemanusiaaan.

2. Kinerja Karyawan

Kinerja karyawan sangat di perlukan untuk meningkatkan daya saing perusahaan, semakin baik kinerja 
karyawan maka semakin baik kinerja perusahaan". Menurut Sutrisno (2017 : 151), "Kinerja adalah hasil kerja yang telah dicapai sesorang dari tingkah laku kerjanya dalam melaksanakan aktifitas kerja".

\section{METODE}

Metode penelitian ini menggunakan penelitian asosiatif. Populasi dan sampel yang digunakan sebanyak 45 responden dan menggunakan teknik sampling jenuh. Analisa data menggunakan regresi linear sederhana serta menggunakan bantuan software SPSS versi 24. Pengumpulan data primer dilakukan dengan cara observasi, kuesioner, sedangkan data sekunder dari sumber-sumber data-data PT Sentra Ponselindo, buku-buku, artikel, dan jurnal.

\section{HASIL DAN PEMBAHASAN}

Berdasarkan hasil analisa, instrument disiplin kerja $(X)$ dan instrument kinerja $(\mathrm{Y})$ yang terdiri dari 16 (enam belas) instrument. Nilai $r$ hitung $>r$ tabel $(0,294)$ dengan taraf $5 \%$, maka butir instrument dinyatakan valid, artinya seluruh butir instrument sudah tepat menjadi alat ukur.

Analisa pada instrument disiplin kerja $(X)$, menunjukkan koefisien reliabilitas (r11) sebesar 0,807>0,600 maka butir instrument dinyatakan reliabel, artinya instrumen dapat dipercaya untuk mengumpulkan data penelitian.

Analisa pada instrument kinerja $(\mathrm{Y})$, menunjukkan koefisien reliabilitas (r11) sebesar $0,777>0,600$ maka butir instrument dinyatakan reliabel, artinya instrumen dapat dipercaya untuk mengumpulkan data penelitian.

Hasil output normalitas didapatkan Asymp. Sig. (2-tailed) sebesar 0,200 > 0,05 maka Ho diterima artinya data terdistribusi normal, dengan demikian model regresi telah memenuhi asumsi normalitas.

Terdapat Pengaruh Positif Antara Variabel Disiplin Kerja (X) Terhadap Variabel Kinerja (Y). Constanta a $=32,207$ bermakna, jika tidak ada perubahan pada variabel DIisplin Kerja $(X)$ atau variabel bebas bernilai tetap, maka nilai variabel Kinerja (Y) sebesar 32,207. Koefisien regresi $b=0,496$ bermakna, jika terjadi kenaikan satu-satuan pada variabel Disiplin Kerja $(X)$ maka nilai Variabel Kinerja (Y) akan bertambah sebesar 0,496.

Didapat nilai korelasi $\mathrm{R}$ sebesar 0,529 , nilai ini masuk ke dalam rentang antara 0,400 - 0,599 dengan tingkat hubungan sedang, maka dapat disimpulkan bahwa, variabel Disiplin Kerja (X) memiliki tingkat hubungan Sedang terhadap variabel Kinerja $(Y)$

Nilai R Square didapat sebesar 0,279 $(0,279 \times 100 \%=27,9 \%)$ maka dapat disimpulkan bahwa, disiplin kerja $(X)$ memiliki kontribusi terhadap kinerja (Y) sebesar $27,9 \%$ dan sisanya $72,1 \%$ dipengaruhi oleh faktor lain yang tidak diteliti.

Didapatkan thitung 4,084 > t tabel 2,017 dengan taraf 5\% maka Ha diterima dan $\mathrm{H} 0$ ditolak maka dalam penelitian ini menetapkan bahwa terdapat pengaruh positif dan signifikan antara disiplin kerja $(\mathrm{X})$ terhadap kinerja karyawan $(\mathrm{Y})$ pada PT Sentra Ponselindo.

\section{KESIMPULAN DAN SARAN Kesimpulan}

Berdasarkan hasil penelitian dan pembahasan yang sudah dilakukan, dapat disimpulkan, bahwa terdapat pengaruh positif dan signifikan antara disiplin kerja (X) terhadap kinerja karyawan (Y) Pada PT Sentra Ponselindo. Hasil analisa menghasilkan persamaan $\mathrm{Y}=32,207+$ 0,496X, persamaan ini dapat disimpulkan bahwa terdapat arah pengaruh positif antara variabel disiplin kerja $(X)$ terhadap variabel kinerja $(\mathrm{Y})$. Koefisien korelasi $\mathrm{R}$ sebesar 0,529, variabel disiplin kerja $(X)$ memiliki tingkat hubungan sedang terhadap variabel Kinerja (Y). Koefisien determinasi $\mathrm{R}$ Square sebesar 0,279, kontribusi terhadap kinerja $(\mathrm{Y})$ sebesar $27,9 \%$ dan sisanya $72,1 \%$ dipengaruhi oleh faktor lain yang tidak diteliti. Hasil uji hipotesis parsial menunjukkan nilai thitung 4,084 > t tabel 2,017 dengan taraf 
5\% , maka Ha diterima dan H0 ditolak, maka dalam penelitian ini menetapkan bahwa terdapat pengaruh positif dan signifikan antara disiplin kerja $(X)$ terhadap kinerja karyawan (Y) pada PT Sentra Ponselindo.

\section{Saran}

Saran yang dapat diberikan sebagai bahan pertimbangan dalam meningkatkan disiplin dan kinerja karyawan adalah pemberian sangsi agar lebih memberikan efek jera bagi karyawan yang melanggar peraturan dan agar atasan lebih tegas dalam menindak pelanggaran peraturan. Kinerja karyawan diharapkan agar mampu mencapai target kerja yang diberikan, serta karyawan mampu meningkatkan pengetahuan dan keahlian

\section{DAFTAR PUSTAKA}

Bangun, Wilson. (2016). "Manajemen Sumber Daya Manusia". Bandung: Erlangga.

Bisnis". Cetakan ke 15. Bandung: Alfabet. Gaol, CHR. Jimmy L,. (2014). "A to Z Human Capital (Manajemen Sumber Daya Manusia) Konsep, Teori, dan Pengembangan dalam Konteks Organisasi Publik dan Bisnis". Jakarta: PT. Gramedia Widiasarana.

Ghozali, Imam. (2016). “Aplikasi Analisis Multivariate Dengan Program IBM SPSS 23". Edisi Kedelapan Setalan Kedelapan. Semarang: Badan Penerbit Universitas Diponegoro.

Hartatik, Indah Puji. (2014). “Buku Praktis Mengembangkan SDM". Yokyakarta: Laksana.

Hasibuan, S. P, Malayu. (2016). "Manajemen Sumber Daya Manusia". Jakarta: Bumi Aksara.

Insani, P. B. E. B. (2020). Hubungan Gaya Kepemimpinan Dengan Produktivitas Kerja Pegawai Bmt El Bina Insani Cugenang. Jurnal Agrita Vol, 2(1).

Kristianti, L. S., et al (2021). Pengaruh Motivasi Dan Disiplin Kerja Terhadap Kinerja Pegawai Pada Dinas Pariwisata Purwakarta. Jurnal
Ilmiah PERKUSI, 1(1), 101-109.

Mangkunegara, Anwar Prabu (2016). "Manajemen Sumber Daya Manusia Perusahaan". Bandung: Remaja Rosdakarya.

Moekijat. (2014). "Manajemen Personalia Dan Sumber Daya Manusia". Bandung:Mandar Maju.

Noelaka. Amos. (2014). "Metode Penelitian Dan Statistik". Jakarta: Remaja Rosdakarya.

Nurjaya, N., et al (2021). Pengaruh Etos Kerja Dan Disiplin Kerja Terhadap Kinerja Pegawai Pada Dinas Kehutanan Dan Perkebunan Kota Bogor. JENIUS (Jurnal Ilmiah Manajemen Sumber Daya Manusia), 4(2), 172-184.

Paramarta, V., et al (2021). Halal Tourism in Indonesia: Regional Regulation and Indonesian Ulama Council Perspective. International Journal of Criminology and Sociology, 10, 497505.

Permatasari, R. J. (2018). Analisis Pengaruh Pendidikan Dan Pelatihan, Motivasi Dan Kompensasi Terhadap Kinerja Karyawan (Pada Citibank Pondok Indah Jakarta Selatan). JENIUS (Jurnal Ilmiah Manajemen Sumber Daya Manusia), 1(3).

Sedarmayanti. (2014). "Manajemen Sumber Daya Manusia". Bandung: Refika Aditama.

Silaen, Sofar. (2018). "Metodologi Penelitian Sosial Untuk Penulisan Skripsi dan Tesis". Bandung: In Media, Bandung.

Simamora, Henry. (2014). "Manajemen Sumber Daya Manusia". Yogyakarta: Sekolah Tinggi Ilmu Ekonomi YKPN.

Siregar, Syofian. (2014). "Satatistik Parametrik Untuk Penelitian Kuantitatif:. Jakarta: Bumi Aksara.

Siswanto. Bejo. (2013). "Manajemen Tenaga Kerja Indonesia, Pendekatan Administratif dan Operasional." Jakarta:Bumi Aksara.

Sugiyono. (2015). “Metode Penelitian

Suharsini Arikunto. Prosedur Penelitian, 
Penerbit : Rineka Cipta, Jakarta, 2014

Sujarweni, V. Wiratna. (2016). “Kupas

Tuntas Penelitian Akuntansi dengan SPSS". Yogyakarta: Pustaka Baru Press.

Suprihatin, L., \& Gunarda, G. (2019). Pengaruh Disiplin Dan Kompensasi Terhadap Kinerja Pegawai Di Pusat Pendidikan Dan Pelatihan Pegawai
Kementerian Pendidikan Dan Kebudayaan. JENIUS (Jurnal Ilmiah Manajemen Sumber Daya Manusia), 2(2), 278-289.

Sutrisno, Edy. (2017). “Manajemen Personalia Dan Manajemen Sumber Daya Manusia". Jakarta: Prenada Media Group. 